\title{
Integrating Social Networking Tools into ESL Writing Classroom: Strengths and Weaknesses
}

\author{
Melor Md Yunus ${ }^{1}$, Hadi Salehi ${ }^{2} \&$ Chen Chenzi ${ }^{1}$ \\ ${ }^{1}$ Faculty of Education, Universiti Kebangsaan Malaysia, Malaysia \\ ${ }^{2}$ Faculty of Literature and Humanities, Najafabad Branch, Islamic Azad University, Najafabad, Isfahan, Iran \\ Correspondence: Hadi Salehi, Faculty of Literature and Humanities, Najafabad Branch, Islamic Azad University, \\ Najafabad, Isfahan, Iran. Tel: 60-176-538-260. E-mail: hadisalehi1358@yahoo.com
}

Received: April 23, 2012 Accepted: May 25, 2012 Online Published: July 2, 2012

doi:10.5539/elt.v5n8p42 URL: http://dx.doi.org/10.5539/elt.v5n8p42

\begin{abstract}
With the rapid development of world and technology, English learning has become more important. Teachers frequently use teacher-centered pedagogy that leads to lack of interaction with students. This paper aims to investigate the advantages and disadvantages of integrating social networking tools into ESL writing classroom and discuss the ways to plan activities by integrating social networking services (SNSs) into the classroom. Data was collected through an online discussion board from TESL students in a state university in Malaysia. The findings revealed that integrating social networking services in ESL writing classroom could help to broaden students' knowledge, increase their motivation and build confidence in learning ESL writing. The students' difficulties for concentrating on the materials when they use computer, lack of enough equipment as well as access to internet, and teachers' insufficient time to interact with the students were regarded as the main disadvantages of integrating social networking tools into ESL writing classes. Therefore, in this new technological era, it is essential for students and teachers to be equipped with technical skills to be competent for life-long learning and teaching. More studies are needed to explore the teachers' and students' attitudes towards using ICT in ESL/EFL contexts. Future quantitative and qualitative studies with more participants are needed to provide deeper insight.
\end{abstract}

Keywords: Social Networking Services (SNSs), integration, facebook, Wikipedia, ESL writing

\section{Introduction}

A social networking service (SNS) is an online platform or medium used to establish social networks or social relations among individuals who share interests and activities (Wikipedia, 2010). Most social networking services allow users to share their opinions, interests, activities and events within their individual networks. The SNSs are web based and provide means for users to interact over the internet in various ways such as e-mail or instant messaging. Among various kinds of social networking services, Facebook and Twitter are widely used worldwide; MySpace and LinkedIn being the most widely used in North America, Friendster, RenRen and CY are well known in Asia, and in India, Orkut is the most famous one.

According to Boyd and Ellison (2007), SNSs are web-based services that allow individuals to construct a public or semi-public profile within a bounded system, articulate a list of other users with whom they share a connection, and view the pages and details provided by other users within the system. Ahmad (2011) believes that SNSs have evolved as a combination of personalized media experience within social context of participation. He makes a distinction between SNSs and other types of computer-mediated communications because in SNSs, profiles are publicly viewed, friends are publicly articulated, and comments are publicly visible.

Boyd and Ellison (2007) claimed that social networking sites not only allow individuals to meet strangers, but also enable users to articulate and make visible their social networks. They claim that on many of the large SNSs, users are not necessarily looking to meet new people; "instead, they are primarily communicating with people who are already a part of their extended social network" (p. 210). In general, social networking services are developing in an amazing rapid pace and excellently connect the individuals. The implications of social networking services have developed in variety of areas and domains. Since social networking services have 
received and demonstrated such a good effort, it is possible for us to discuss how they will work around education fields.

\section{Literature Review}

\subsection{Integrating SNSS into ESL Writing Classroom}

Online learning refers to the learning environment that uses Internet technology to enable virtual learning session. According to Taranto, Dalbon, and Gaetano (2011), as the world becomes more and more connected through advances in information and communication technologies, classroom experiences need to reflect those same changes. Moreover, teachers of students who regularly use Web 2.0 technologies need to develop an understanding of new digital literacy and infuse them with their curricular planning and classroom practices (Greenhow, Robelia, and Hughes, 2009). In order to investigate how exactly SNSs serve for teaching ESL writing, Facebook and Wikipedia were chosen to be discussed here.

\subsubsection{Constructing Virtual Classroom through Facebook}

Yang (2008) stated that as students' online diary, blog can be used to teach writing, and teacher could ask students who use blog to post their compositions regularly. They can choose their best compositions per terms, each composition should contain all the writing process from construct to edit, this action can be done on Facebook, too. Facebook owns an application called Note which actually functions as a simpler Blog. Yang (2008) also commented that teacher and students can treat Blog as a 'blackboard' and teacher can save all the students' works. Furthermore, teacher can post and introduce articles to students; students could chain their blogs in order to share information. Apparently, this is much easier for Facebook users. Additionally, Yang (2008) applauds Blog as a free publish place, teachers have the responsibility to offer students chances to publish their works and share with others. Hence, Blog offers convenience to this action, so does Facebook.

According to Russell et al., (2003), teachers engaged with a technological tool are more likely to employ that technological medium in their teaching and curricular planning. Pre-service teachers should encourage their students to implement Facebook in the classroom activities and focus on integrating Facebook into the course content and objectives. However, when implementing Facebook, pre-service teachers should consider a pedagogical rationale for using Facebook as well as its applications.

In order to create a virtual classroom, Munoz and Towner (2009) mentioned that the teachers can ask the students to create their own Facebook account and become friends with at least another member of the class. Then, the teachers should help the students to post appropriate and class-related images, and messages about the assignments and events. Munoz and Towner (2009) made the following specific steps to construct a virtual classroom through Facebook.

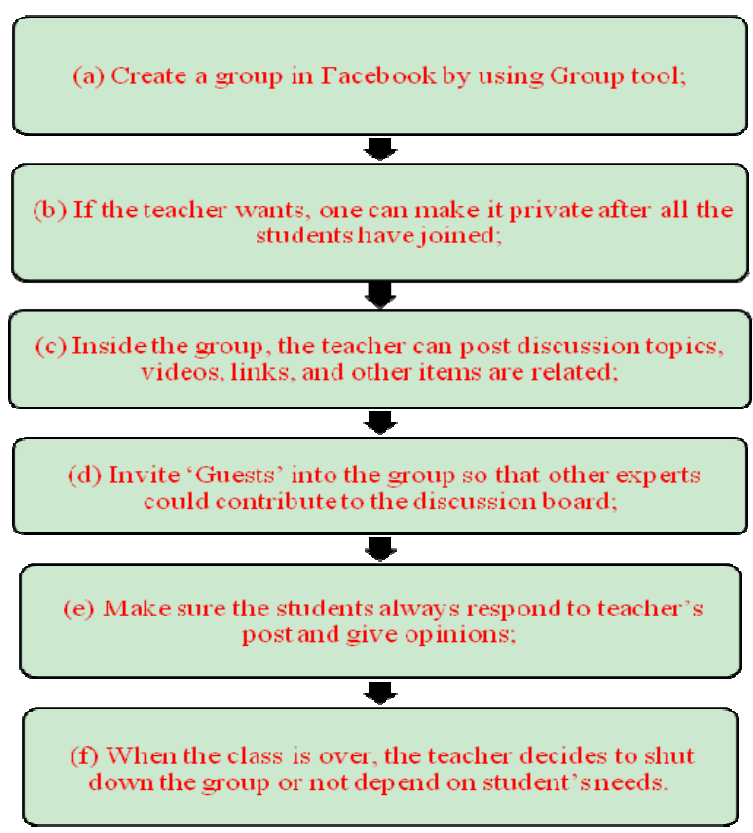

Figure 1. Steps to Construct a Virtual Classroom through Facebook 
Moreover, Lenhart and Madden (2007) emphasized that the classroom Facebook page should be only related to the classroom and unrelated things should not be on that page. The page should be a digital representation of the class and curriculum, not a page that is strictly teacher-oriented.

\subsubsection{Wikipedia as a Discussion Forum}

According to Grandzol and Grandzol (2010), in an advanced English class, Wikipedia can be utilized as a forum to discuss different ideas and thoughts about books the students have read independently. Since these books have been discussed exclusively on the wiki, the discussions are student-centered and student driven. Taranto, Dalbon and Gaetano (2011) also claimed that while the wiki acts as a kind of moderator, the students are actually the driving force behind each discussion. The students "question, challenge, and respond to one another in a fast-paced, equal-opportunity environment with which they are extremely familiar; this mimics many of their social interactions on the Web outside of school" (p. 13).

Teachers can also share some useful information about their teaching contents and some reading materials for students to read. They can also create forums for classroom discussion as well as post assignments, tests and quizzes, to assist their teaching outside of the classroom setting (Wikipedia, 2010). On this forum, teachers and students take part in discussions based on topics. Teachers can require students to post book review, or ask them to write lesson reflections. Moreover, the students were able to see their peers' works and give comments. It is indubitably an efficient way to improve both students' writing skills and their creative thinking skills.

\subsection{Advantages of Integrating SNSs into ESL Writing Classroom}

Warnock (2009) stated that the first reason to teach writing online is that the environment can be purely textual. Students are in a rich, guided learning environment in which they express themselves to a varied audience with their written words. The electronic communication tools allow students to write to the teacher and to each other in ways that will open up teaching and learning opportunities for everyone involved. Besides, writing teachers have a unique opportunity because writing-centered online courses allow instructors and students to interact in ways beyond content delivery. They allow students to build a community through electronic means. For students whose options are limited, these electronic communities can build the social and professional connections that constitute some of education's real value (Warnock, 2009).

Moreover, Melor (2007) pointed out that social interaction technologies have great benefits for lifelong education environments. The social interaction can help enhancing the skills such as the ability to search, to evaluate, to interact meaningfully with tools, and so on. Education activities can usually take place in the classroom which teacher and students will face to face, but now, it can be carried out through the social network technologies including discussion and assessment. According to Kamarul Kabilan, Norlida Ahmad and Zainol Abidin (2010), using Facebook affects learner motivation and strengthens students' social networking practices. What is more, according to Munoz and Towner (2009), Facebook also increases the level of web-based interaction among both teacher-student and student-student. Facebook assists the teachers to connect with their students outside of the classroom and discuss about the assignments, classroom events and useful links.

Hence, social networking services like Facebook can be chosen as the platform to teach ESL writing. Social networking services can contribute to strengthen relationships among teachers as well as between teachers and students. Besides, they can be used for teachers and students to share the ideas, to find the solutions and to hold an online forum when necessary. Using social networking services have more options than when using communication tools which only have single function, such as instant messaging or e-mail. The people can share interests, post, upload variety kinds of media to social networking services so that their friends could find useful information (Wikipedia, 2010).

To sum up, the advantages of integrating SNSs into ESL writing classroom can be listed out as the following:

- Most students now are digital natives, so SNSs engage them by presenting material in a way that is familiar and comfortable for them.

- $\quad$ Students can get enough input from SNSs so they will develop students' writing skills. In SNSs like Blogs and Facebook, teacher's notes can be viewed with chronological order. This is very convenient when preparing lessons that build upon previous materials taught in the class.

- Students will have a larger audience when they use social networking. Working online fosters a sense of global interaction. Students can communicate with their teachers and friends by Blogs or Facebook. This is especially helpful for shy students who might not otherwise reach out. 
- Social networking services allow for multimedia interaction which brings together pictures, videos, links and so on.

- Students will take responsibility for their works because they have a larger audience when they use social networks. This may empower them and their work and leads to self-directed learning.

- Students can read comments for the class as a whole and comments directly and individually on them. This maximizes feedback and contact with the teacher.

- $\quad$ Parents can view their children's work and progress.

\subsection{Disadvantages of Integrating SNSs into ESL Writing Classroom}

The benefits that SNSs tools bring to the classroom can easily be seen. However, excluding the educational functions, SNSs like Facebook, Blog, or Twitter are still serving us as entertainment on a large degree. Therefore, inserting SNSs into ESL classroom may cause students' distraction. Besides, sometimes online teacher-student relationship could be tricky. Simon (2008) claimed that SNSs help students to connect with their teachers and discuss about homework, tutoring and other school matters. However, some researchers claim that SNSs have the potentiality to breed inappropriate relationships between teachers and students. For example, according to Simon (2008), some student-teacher sexual relationships have spawned crackdowns on social-networking friendships. He stated that the website badbadteacher.com, which keeps track of teachers disciplined, arrested and convicted of inappropriate behavior with students, lists 11 such teachers from Missouri within the last two years (Simon, 2008).

Teachers can create the online forums in Facebook to teach writing; however, they need to know how to invite students appropriately, not forcing them to join. It is also a challenge for the teachers. The teachers are recommended to create online forums for those students who intend to join, rather than forcing them to participate (Munoz and Towner, 2009).

According to Richard et al., (2008), the lack of technological devices in schools, the teachers' unawareness of available ICT teaching resources as well as insufficient theoretical and practical training of the teachers prevent the teachers to successfully integrate technology into teaching and learning environments. The more student-teacher interaction that occurs in university courses online, the more likely it is that distance learners will drop out of class. As Grandzol and Grandzol (2010) claim, requiring student interaction just for the sake of interaction may lead to diminished completion rates. It is a challenge for students to control themselves to study online.

According to Kamarul Kabilan, Norlida Ahmad and Zainol Abidin (2010), using facebook may waste time, encourage negative attitudes (such as lying) and affect students' social growth detrimentally. It is the challenge for both students and teachers to arrange their time and also it is the challenge for students' social growth. Rosenblum (2007) pointed out that social networking services are easy to access; therefore, shared content and personal diaries can be viewed by any user who is interested in the personal information of other users. Sometimes parents may use the children's account number to enter and read the privacy personal information in the social networking websites. In general, the disadvantages of integrating SNSs into ESL writing classroom can be sorted out as the following:

- The relationship between teacher and students can somehow be tricky. Teachers need to realize that even though the environment is virtual, the identity should not be hidden.

- It takes time to design, edit and modify digital learning materials for teachers. Sometimes it is time-consuming and frustrating to search for the materials online. Moreover, the learners will be encountered with a pool of information with little control over the quality and accuracy of the content.

- The learners must have access to computer and internet. Hence, when the technology is not reliable or the internet is not available, the learners will be faced with difficulties.

- Some learners find it so difficult to read the materials online because they are accustomed to the traditional book-centered approach.

- Students will spare more time on playing computer games and chatting on-line on the pretext of doing writing on internet.

- Writing tasks online will lead students to 'copy-paste' from the extensive online resources without thinking.

In view of examining the advantages and disadvantages of integrating SNSs into ESL writing classroom, this study was conducted to explore the ways to plan activities by integrating SNSs into the classroom. 


\section{Methodology}

This part mainly deals with the methodology used in this study, which consists of three sections namely the research design, research instrument and data collection procedures.

\subsection{Research Design}

The design of this study is qualitative in nature. By using an online discussion board, a discussion was held among the participants. The employed online discussion board is an e-learning platform and a web-based courseware delivery engine that uses multimedia to increase the level of teaching and learning process. The participants were fifteen third-year TESL students (e males and 12 females) in a state university in Malaysia who were randomly selected to discuss willingly about the research questions. The participants could access the subject matter anytime and anyplace via an internet connection. The researchers posted questions on the discussion board and the participants replied and reacted to the questions. The TESL students were chosen because they had a better understanding or experience of the SNSs.

\subsection{Research Instrument}

The instruments were three open ended questions which aimed to investigate teacher-trainees' opinions about integrating SNSs into ESL writing classroom. The questions were about the advantages and disadvantages of using SNSs in teaching ESL writing and the ways to plan activities by integrating SNSs into the classroom. The participants were free to give opinions and they were extremely encouraged to interact and reply to each other's comments.

\subsection{Data Collection Procedure}

For the data collection procedure, the researchers uploaded three open-ended questions on the online discussion board, and the participants were requested to answer the questions and interact with each other during the discussion period. After two weeks, the discussion was completed and the discussion contents were collected. The data were coded, categorized and interpreted. Then the comments were analyzed and reported by using quotes from the participants' opinions.

\section{Results and Discussion}

Fifteen TESL students were involved in the online discussion. Three students were male and twelve were female. Most of them have been studying English more than ten years. All of them have computer and internet at home and they also could get internet in school or internet bars. According to the discussion content, students do not often use social networking services in learning English. They frequently use instant messaging to chat in English as well as search information in social networking services.

Most of the students believe that using social networking services to teach ESL writing brings a lot of benefits. For example, students with lower language skills could interact with the other students with less stress. Using social networking services such as Facebook to teach ESL writing could trigger students' creative thinking skills. However, there are some weaknesses to integrate social networking tools into ESL writing classroom. For instance, internet distraction and informal writing habits such as using short forms are regarded as the main challenges. About the activity, most of the participants like using Facebook to create a virtual classroom to cultivate students' brainstorming ability as well as thinking skills.

To summarize the findings and to achieve the purpose of the study, the main findings are categorized based on the three following issues:

\section{Planning Activities to Integrate SNSs into ESL Writing}

There are plenty of activities that can be planned through social networking services but group brainstorming seems to be the most efficient one. Students are able to share more than just their thoughts, but to share photos, videos and documents. One of the male participants referred to Facebook groups as a means that can be integrated into teaching activities. He stated that:

"Facebook groups" function has the element of interactivity. ... [teachers] can use Facebook groups to brainstorm for ideas. They can just give their initial response, their first reaction to the topic that is to be discussed. They can share photos for visual stimulus and activating schemata. They can share links to websites that have more information on the topic being discussed. Teachers [need] to guide students closely so there is some coherence in the information that is shared by all the students in the class.

These could all be resources for brainstorming. Through online discussion and group brainstorming, students' critical thinking skills can be trained. Moreover, through writing reflection in the group, students will gain peer-work skill and can develop their expression ability better. 


\section{Advantages of Using Social Networking Tools in Teaching ESL Writing}

The advantages of integrating social networking services in ESL writing classrooms are as the following:

1) They enhance outside classroom interaction and education between the students and the teacher; 2) they help to broaden students' knowledge; 3) they increase motivation and build confidence for students in using and learning English; 4) they train students' thinking skills and writing skills; 5) they help students to build and improve their vocabulary; 6) they provide a platform for teacher to prepare the lesson efficiently such as pre-writing preparation; and 7) they provide large amount of information that can be shared between the teacher and students.

\section{Disadvantages of Using Social Networking Tools in Teaching ESL Writing}

The first disadvantage is that students might not concentrate on learning when they use computer online. One of the female participants referred to the problem of distraction as she said:

... it is true indeed that the distraction is the main disadvantage of using social networks for teaching writing. Yeah, just take myself as the example. When I am looking for information about my assignments, I tend to get distracted by looking for a while at the status update at Facebook homepage.

Moreover, informal short forms appear increasingly and they will affect students' actual writing. One of the male participants stated that:

The usage of short forms and abbreviations does not create positive learning environment because the habit of using too much short forms in writing may make students have the habit of using short forms even in the formal writing tasks in school.

Besides, some social networking services make corrections automatically; if students get use to this, they will even forget how to spell a single word correctly. One more point is that there is no guarantee that all the information online is correct; it might mislead students in their language acquisition.

In general, teachers should realize that even though they are always considered as instructor, somehow teacher-centered teaching may direct students in a way to learn passively. Especially in writing classroom, lack of communication can make the learning environment boring. Besides, students' creative thinking cannot be triggered effectively by just listening to whatever teacher asks them to do. While teacher functions as a facilitator in virtual online classroom, students will be more relaxed to train their writing skills.

The most difficult aspect in academic writing is that students feel they have nothing to write because their minds are blank and there is no inspiration. If a teacher encourages students to write blogs often, students may see people around them and share their feelings and thoughts because even just recording a conversation will help students to store writing materials. Moreover, through reading each other's blogs and comments, students can be inspired by their friends' words.

\section{Conclusion}

In conclusion, to increase students' interests in writing, they need to have some confidence. If teachers manage time to read students' blogs or notes online, students will be motivated to have some potential readers. After reading students' blogs, teacher should make comments on the blog, pick out their excellent sentences or points and praise them. Therefore, students will be encouraged and they might try to write more excellent sentences in the future. Another advantage is that when giving writing tasks to the students, teachers should give students topics related to their real life. Such topics are more interesting and easier for students to discuss about. These topics motivate students to write.

Using brainstorming strategy not only helps students store ideas for writing but also improves their creative thinking skills. Since they are writing through SNSs, shy students will not be afraid to write out loud. During the discussion stage, students are exchanging ideas so that their critical thinking skills will be improved. Social networking services provide a better opportunity for interaction, planning and getting more information. In general, it could be effective for students to learn ESL writing if teachers encourage students to brainstorm through SNSs.

Teachers should try to give students choices, responsibilities and opportunities to interact while they write. Even though it is not easy for teachers to apply new activities and tools in the classroom, they should improve their ICT skills and get familiar with the SNSs. And once the SNSs are integrated into ESL writing classroom, students will be more interested in writing so that their writing skills will be improved. 


\section{References}

Ahmad, A. (2011). A short description of social networking websites and its uses. International Journal of Advanced Computer Science and Applications (IJACSA), 2(2), 124-128.

Bosch, T. E. (2009). Using online social networking for teaching and learning: Facebook use at the University of Cape Town. Communicatio, 35(2), 185-200. http://dx.doi.org/10.1080/02500160903250648

Boyd, D., \& Ellison N. (2007). Social network sites: Definition, history and scholarship. Journal of Computer-Mediated Communication, 13(1), 210-230. http://dx.doi.org/10.1111/j.1083-6101.2007.00393.x

Grandzol, C. J., \& Grandzol, J. R. (2010). Interaction in online courses: More is not always better. Online Journal of Distance Learning Administration, 13(2). Retrieved from http://www.westga.edu/ distance/ojdla/summer132/Grandzol_Grandzol132.pdf

Greenhow, C., Robelia, B., \& Hughes, J. (2009). Learning, teaching, and scholarship in a digital age: Web 2.0 and classroom research: What path should we take now? Educational Researcher, 38, 246-259.

Kamarul Kabilan, M., Norlida Ahmad, \& Zainol Abidin, M. J. (2010). Facebook: An online environment for learning of English in institutions of higher education? The Internet and Higher Education, 13(4), 179-187. http://dx.doi.org/10.1016/j.iheduc.2010.07.003

Lenhart, A., \& Madden, M. (2007). Social networking websites and teens: An overview. Retrieved from http://www.pewinternet.org/ /media//Files/Reports/2007/PIP_SNS_Data_Memo_Jan_2007.pdf.pdf

Melor Md Yunus. (2007). Malaysian ESL teachers' use of ICT in their classrooms: expectations and realities. RECALL: The Journal of EUROCALL, 9(1), 79-95.

Munoz, C., \& Towner, T. (2009). Opening Facebook: How to use Facebook in the college classroom. In I. Gibson et al. (Eds.), Proceedings of Society for Information Technology \& Teacher Education International Conference. pp. 2623-2627. Chesapeake, VA: AACE.

Richard, P. R., Cobo, P., Fortuny, J. M., \& Hohenwarter, M. (2008). Training teachers to manage problem-solving classes with computer support. In J. Luca, \& E. Weippl (Eds.), Proceedings of World Conference on Educational Multimedia, Hypermedia and Telecommunications. pp. 3520-3530. Chesapeake, VA: AACE.

Rosenblum, D. (2007). What anyone can know: The privacy risks of social networking sites. IEEE Security and Privacy, 5(3), 40-49. http://dx.doi.org/10.1109/MSP.2007.75

Russell, M., Bebell, D., O’Dwyer, \& O'Connor, K. (2003). Examining teaching technology use: Implications for preservice and inservice teacher preparation. Journal of Teacher Education, 54, 297-310. http://dx.doi.org/10.1177/0022487103255985

Simon, M., (2008). Online student-teacher friendships can be tricky. Retrieved from http://articles.cnn.com/2008-08-12/tech/studentsteachers.online_1_facebook-users-myspace-social-networki ng-sites?_s=PM:TECH

Taranto, G., Dalbon, M., \& Gaetano, J. (2011). Academic social networking brings Web 2.0 technologies to the middle grades. Middle School Journal, May 2011, 12-19. Retrieved from http://cmsd.k12.pa.us/cmsd/cm_intsafe/documents/MiddleSchoolJournalArticleMay2011.pdf

Warnock, S. (2009). Teaching writing online: How and why. Urbana: National Council of Teachers of English (NCTE).

Wikipedia. (2010). Social network service. Retrieved from http://en.wikipedia.org/wiki/Social_network_service

Yang, L. (2008). Blog use in composition teaching (In Chinese). Retrieved from http://www.eywedu.com/xkcjcjy/xink2008/xink20080688.html 